\title{
EXPERIENCE WITH POLYMER THICK FILM TECHNOLOGY
}

\author{
RAIMO HULKKONEN, EERO JARVINEN ${ }^{\dagger}$ and VESA SORTTI ${ }^{\dagger \dagger}$ \\ Technical Research Centre of Finland, Electronics Laboratory, Box 181, SF-90101 Oulu 10, Finland
}

(Received October 3, 1981; in final form November 3, 1981)

\begin{abstract}
The paper describes a user's experiences with polymer thick film resistor technology. The characteristics studied are resistance values and their distributing. Parameters affecting these characteristics are the material of the substrate, and the curing of the polymer resistor paste. The test conditions (temperature cycling, dip soldering, high temperature storaging) were chosen to simulate the environmental conditions, through which the polymer resistor circuits have to go during the assembly process of a typical consumer electronics product. The polymer pastes studied were from commercial paste manufacturers in USA, Europe and Japan.

Additional background information, to help in understanding the behaviour of different polymer resistor materials, was obtained through the differential thermo analysis (DTA) of the pastes under investigation.
\end{abstract}

\section{INTRODUCTION}

Polymer thick film technology is a printed circuit manufacturing method, in which polymer resin based conductor, resistor and insulator materials are screen-printed, dried and cured directly on the circuit board. This technology has its effects on size, reliability and productions costs of electronic equipment, by increasing integration, decreasing the number of solder joints and making the automatic insertion of other components easier and more efficient.

To get personal experience and understanding of polymer resistor technology a research project was carried out at the Technical Research Centre of Finland, Electronics Laboratory during the years 1979 and 1980.

The results of this study are presented and discussed in this paper.

\section{INITIAL TESTS}

For the initial tests, several series of polymer resistor test circuits were fabricated using five different kinds of substrate materials. The circuits were then put into tests which simulate conditions which the resistors have to go through before becoming a part of a piece of an electronic equipment. After each test the resistance values were measured and the changes from the initial values were calculated.

\subsection{Description of the Test Circuits}

The substrate materials used in these tests were phenolic paper, bakelite, epoxy glass, anodized aluminum and alumina $\left(96 \% \mathrm{Al}_{2} \mathrm{O}_{3}\right)$. The polymer pastes used in the test circuits were from Electro Materials Corporation of America (EMCA), Electro Science Laboratories (ESL) and Methode Development Company.

\footnotetext{
†Presently with Lohja Corporation, Display Technology, Box 47, SF-08101 Lohja 10, Finland. $\dagger \dagger$ Presently with Aspo Oy Electronics, Box 350, SF-90501 Oulu 50, Finland.
} 


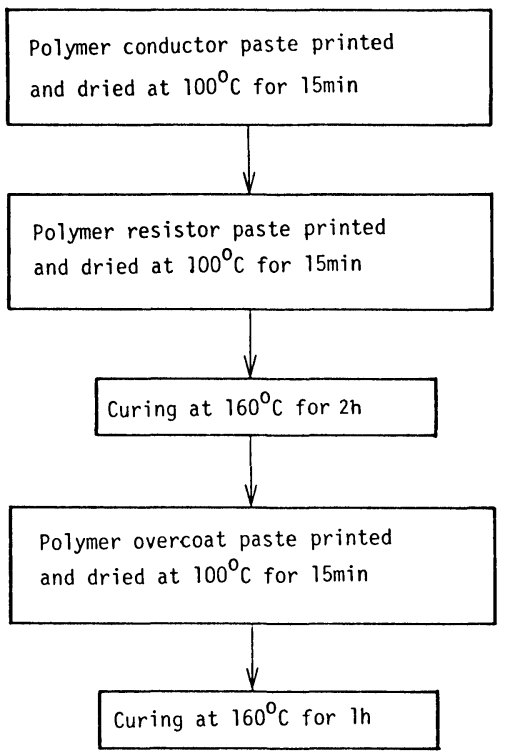

FIGURE 1 The fabrication process of the test circuits.

The curing temperature and time used in the fabrication of the test circuits were within the limits recommended by the paste manufacturers (Figure 1). The printing and curing processes were the same with all the pastes and substrates. In the test circuit there were 32 square shaped resistors, each $3 \mathrm{~mm}$ by $3 \mathrm{~mm}$, and 16 other resistors, their aspect ratios varying from 0,25 to 10 . However, only the results from the square shaped resistors are presented in this paper.

\subsection{Test Program}

The test circuits were put through three different kinds of tests. First they were temperature cycled between $-40^{\circ} \mathrm{C}$ and $+85^{\circ} \mathrm{C}$ for a total of five cycles. This simulated transportation and storaging of the printed circuit boards with polymer resistors before component assembly. Secondly, there was the soldering test which included preheating at $150^{\circ} \mathrm{C}$ for 60 seconds and solder dipping at $250^{\circ} \mathrm{C} \pm 10^{\circ} \mathrm{C}$ for 3 seconds. This simulated the wave soldering process. Thirdly, there was a burn-in test at $+100^{\circ} \mathrm{C}$ for 24 hours. This simulated the aging of a complete electronic equipment before its shipping from the factory.

The test circuits were divided into four groups. One group was in the temperature cycling test, one in the soldering test, one in the burn-in test and the fourth group went through all the three tests.

\subsection{Substrate Effect}

The initial resistance values measured after printing and curing the resistor paste are presented in Figure 2. The sheet resistance values of different resistor materials differ considerably on different substrates. The resistor materials from EMCA and ESL are sensitive to the substrate material, but in relation to each other they behave very much in the same way. On the other hand, the resistor material from Methode is not very sensitive to changes in substrate material, if one ignores the glass fiber epoxy substrate on which 

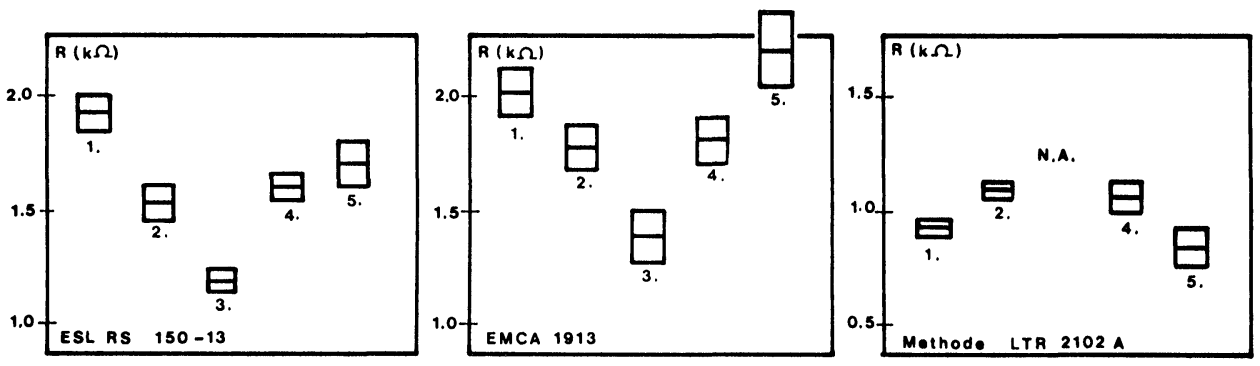

FIGURE 2 Initial resistance values on different substrates $(\mathrm{N}=512,1$.phenolic paper, 2. bakelite, 3. epoxy class, 4 . anadized aluminum, $5 . \mathrm{Al}_{2} \mathrm{O}_{3}, 96 \%$ ).

the resistor material from Methode formed so thin a film that during the curing process most of the resistors were broken.

The substrate effect may be caused by many reasons. One could be that more impervious substrates give higher resistance values, because the polymer portion of the composition is absorbed in the porous substrate leaving carbon on the surface such that the lower resistance of the carbon phase prevails ${ }^{\dagger}$. But this does not explain the whole phenomenon. There has to be some correlation between the behaviour measured from the test circuits and the reactions of the polymer binders, because with different pastes the substrate effect varies. Also the thickness of the resistor films varied, for instance the pastes from EMCA and ESL formed the thickest films on the epoxy glass substrates, which partly explains their lowest resistance values on these substrates.

So, based on this short study, the conclusion is that these pastes are of different types and behave in a different way on the studied substrate materials. For the maker of polymer resistors it is necessary to evaluate the compositions on his substrate material, before proceeding further in his application work.

\subsection{Results from the Applied Tests}

The changes in resistance values after temperature cycling, solder dipping and high temperature storaging are presented in Figure 3.

Temperature cycling increased the resistance values with the paste from EMCA, and decreased with the pastes from ESL and Methode. However, the changes were within 2 per cent of the initial values with all the three pastes (Figure 3a). Solder dipping increased the resistance values 20 to 75 per cent with the pastes from EMCA and ESL and the changes were strongly dependent on the substrate material (Figure $3 b$ ). With the paste from Methode the resistance values decreased 1 to 4 per cent and the changes were much less dependent on the substrate material (Figure 3b). High temperature storage decreased the resistance values on different substrates 1 to 3 per cent with the ESL paste, 1 to 2 per cent with the Methode paste, and 1 to 7 per cent with the EMCA material (Figure 3c). The results of the group which went through every test are presented in Figure $3 \mathrm{~d}$. The resistance values on different substrates increased 10 to 60 per cent with the EMCA paste, and 8 to 40 per cent with the ESL paste. With the Methode paste the resistance values decreased 2 to 6 per cent. In the results the dominance of the solder dipping test can be clearly seen with all three pastes.

\footnotetext{
${ }^{\dagger}$ W.T. Hicks, et al.: - Membrane touch switches: Thick film material systems and processing options. Proc. of ECC 1980.
} 

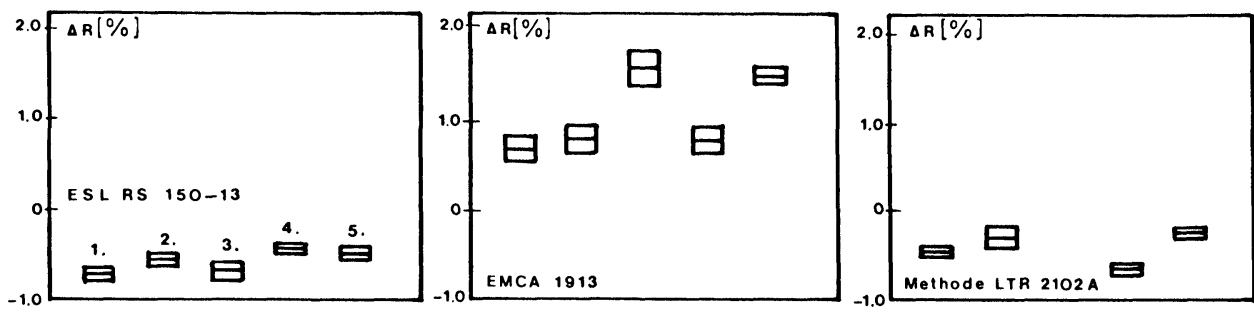

FIGURE 3a Effect of temperature cycling on resistance values $(\mathrm{N}=128)$.

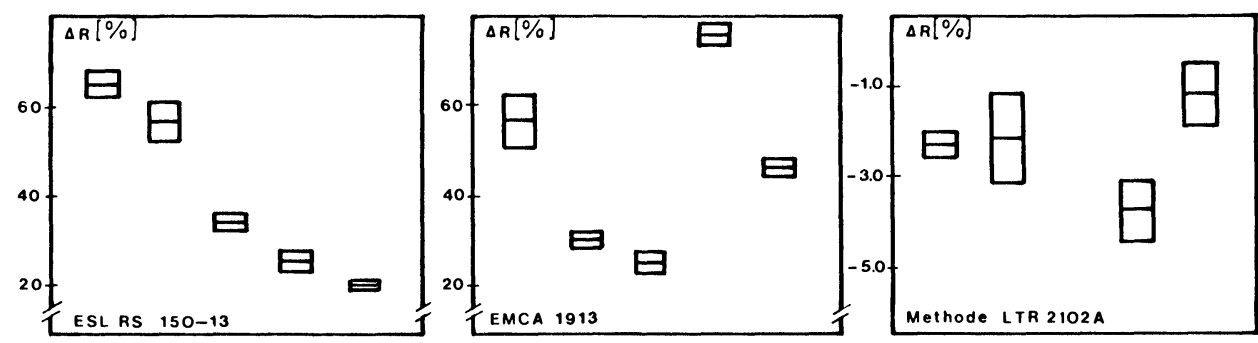

FIGURE 3b Effect of soldering test on resistance values $(N=128)$.

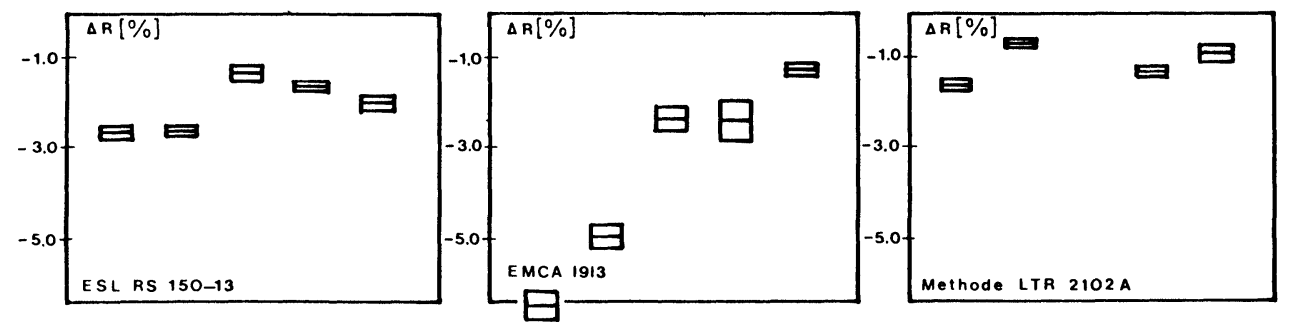

FIGURE 3c Effect of burn-in test on resistance values $(\mathrm{N}=128)$.
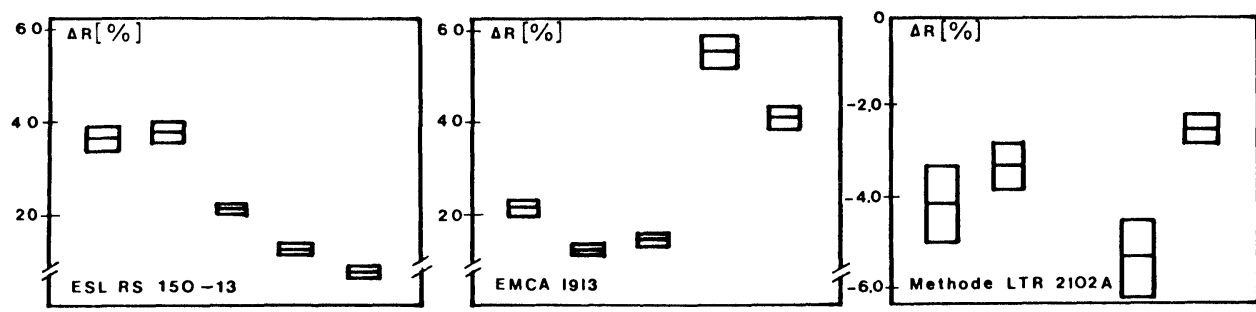

FIGURE 3d Effect of temperature cycling, soldering test and burn-in test on resistance values $(\mathrm{N}=128)$.

When considering the manufacturing process of an electronic equipment, one of the most important factors seems to be the behaviour of polymer resistors in the soldering process. However, these results obtained with dip soldering are not directly applicable to wave soldering, where e.g. the soldering flux has its influence, too. 


\section{FURTHER TESTS}

In the initial tests polymer pastes from EMCA, ESL and Methode were evaluated. After these tests materials were received also from Asahi Chemical Research Laboratories from Japan. The evaluation work was then continued with materials from these four paste manufacturers by examining more deeply the behaviour of polymer resistors in dip soldering and by studying the thermal reactions in the polymeric binders of these pastes.

\subsection{Effect of Soldering Temperature}

A test was arranged where the temperature of the dip soldering bath was changed and the changes in resistance values are measured. The substrate material of the test circuits in this test was alumina which was considered to be an inert material and not to affect the polymeric compositions. The results are presented in Figure 4.

With the pastes from EMCA and ESL the resistance changes increased 10 to 50 per cent and 10 to 20 per cent respectively, when the soldering temperature was changed within the range $220^{\circ} \mathrm{C}$ to $280^{\circ} \mathrm{C}$. With the paste from Asahi the resistance changes were +4 to -3 per cent and with the paste from Methode the resistance changes were 0 to 10 per cent in the same test. Generally, with higher curing temperatures the resistance changes were smaller than with lower curing temperature and this difference was more distinct in the higher soldering temperatures.

\subsection{Effect of Soldering Time}

Another test was arranged where the test circuits were dipped for 3 to 10 seconds in the soldering bath which was held at $250^{\circ} \mathrm{C} \pm 2^{\circ} \mathrm{C}$. The substrate material of the test circuits was alumina in this test, too. The results are presented in Figure 5.

The resistance of polymer resistors seems to be quite insensitive to the length of time the resistors are immersed into the solder bath. The dominant factor seems to be the soldering temperature; at least the absolute resistance changes correlate very well with the
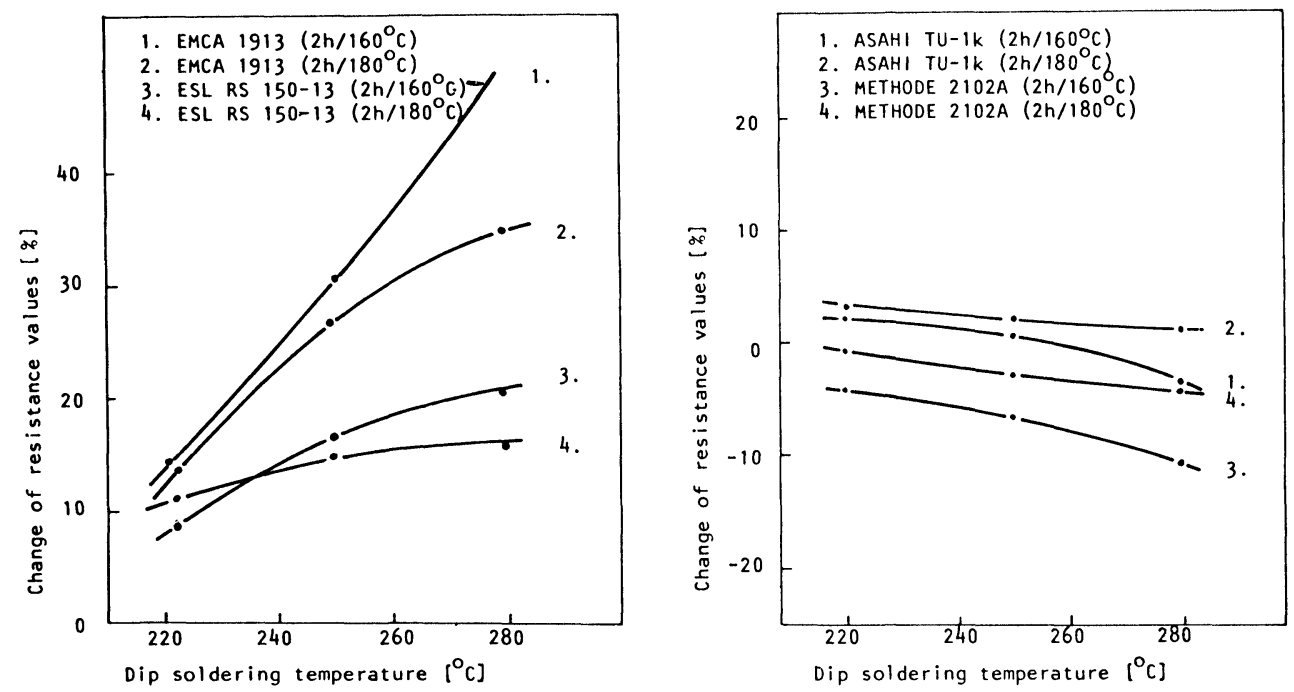

FIGURE 4 Effect of dip soldering temperature on the studied polymer resistor materials. 


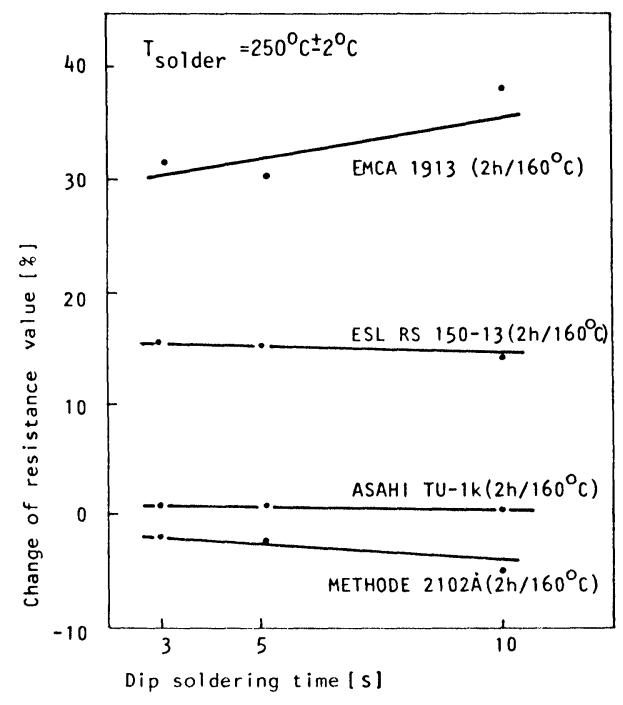

FIGURE 5 Effect of dip soldering time on the studied polymer resistor materials.

results from the soldering temperature test. This test indicates that the resistance changes take place very quickly after the resistor is immersed into the solder bath and the resistance keeps its new changed value independent on the length of time in the solder bath.

\subsection{Differential Thermo Analysis}

In the tests described in the previous sections of this paper the behaviour of polymer resistors varied very much with the materials from different paste manufacturers. In search of means for understanding the behaviour of these materials the air-dried and equal-weight samples of each resistor paste were studied using the differential thermo analysis method. This method reveals the kind of thermal reactions (endothermic, exothermic) taking place in the sample under investigation when it is heated up in a temperature-controlled chamber.

From the obtained DTA-curves (Figure 6.) one can see that the studied pastes differ greatly from each other by their thermal reactions. When trying to correlate these curves with the results from the soldering test, two interesting observations can be made.

First, the pastes from EMCA and ESL, whose resistance values increased in the soldering test, have endothermic reactions around soldering temperatures $\left(240^{\circ} \mathrm{C}\right.$ to $\left.260^{\circ} \mathrm{C}\right)$. On the other hand, the Methode material, whose resistance decreased in the soldering test, has exothermic reactions in these temperatures. When considering the stability of different materials during the soldering test the two most unstable materials, EMCA and ESL, have very distinct transitions from exothermic to endothermic reactions when moving from the curing temperature $\left(160^{\circ} \mathrm{C}\right)$ to the soldering temperatures. This kind of transition does not occur with the Asahi and Methode materials, which proved to be relatively stable materials in the soldering test.

Secondly, the Methode material has a distinct transition from exothermic to endothermic reactions already below the curing temperature. This kind of behaviour, in addition to the thin resistor films mentioned earlier, may have caused high internal tensions in the resistor films during the curing process, which then results in broken resistors on epoxy glass substrates. 

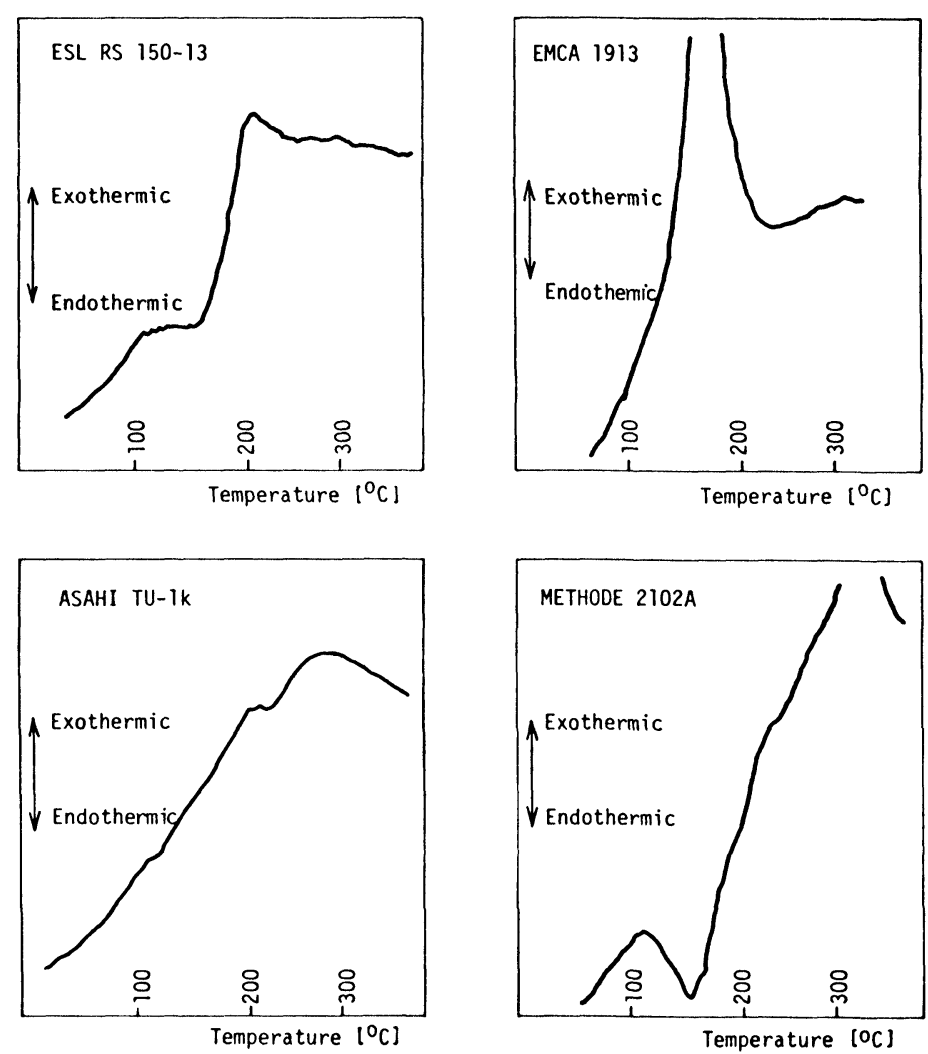

FIGURE 6 DTA-curves of the studied polymer resistor materials (temperature rise $10^{\circ} \mathrm{C} / \mathrm{min}$.).

\section{CONCLUSION}

This study of polymer thick film resistors originated from a practical need for personal experience and understanding of this method for making low-cost printed circuit boards with integrated resistors on the surface. The obtained results were encouraging from the consumer electronics application point of view, although quite large differences were observed between the materials from different paste manufacturers. By carefully evaluating his materials and processing the user should be able to apply polymer resistor technology successfully to many applications. Further development and studied are, however, needed before this technology can be widely used in the electronics industry. 

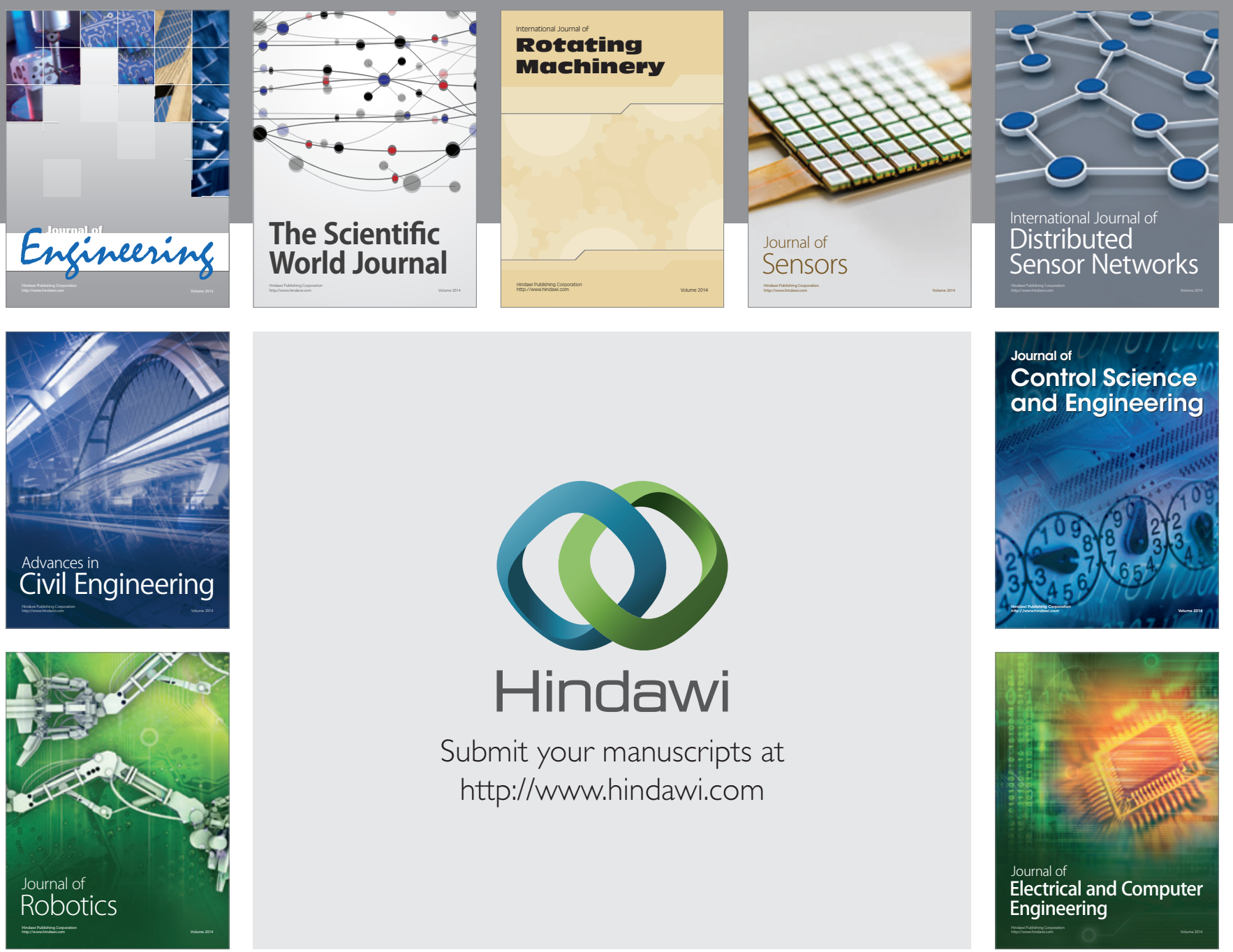

Submit your manuscripts at

http://www.hindawi.com
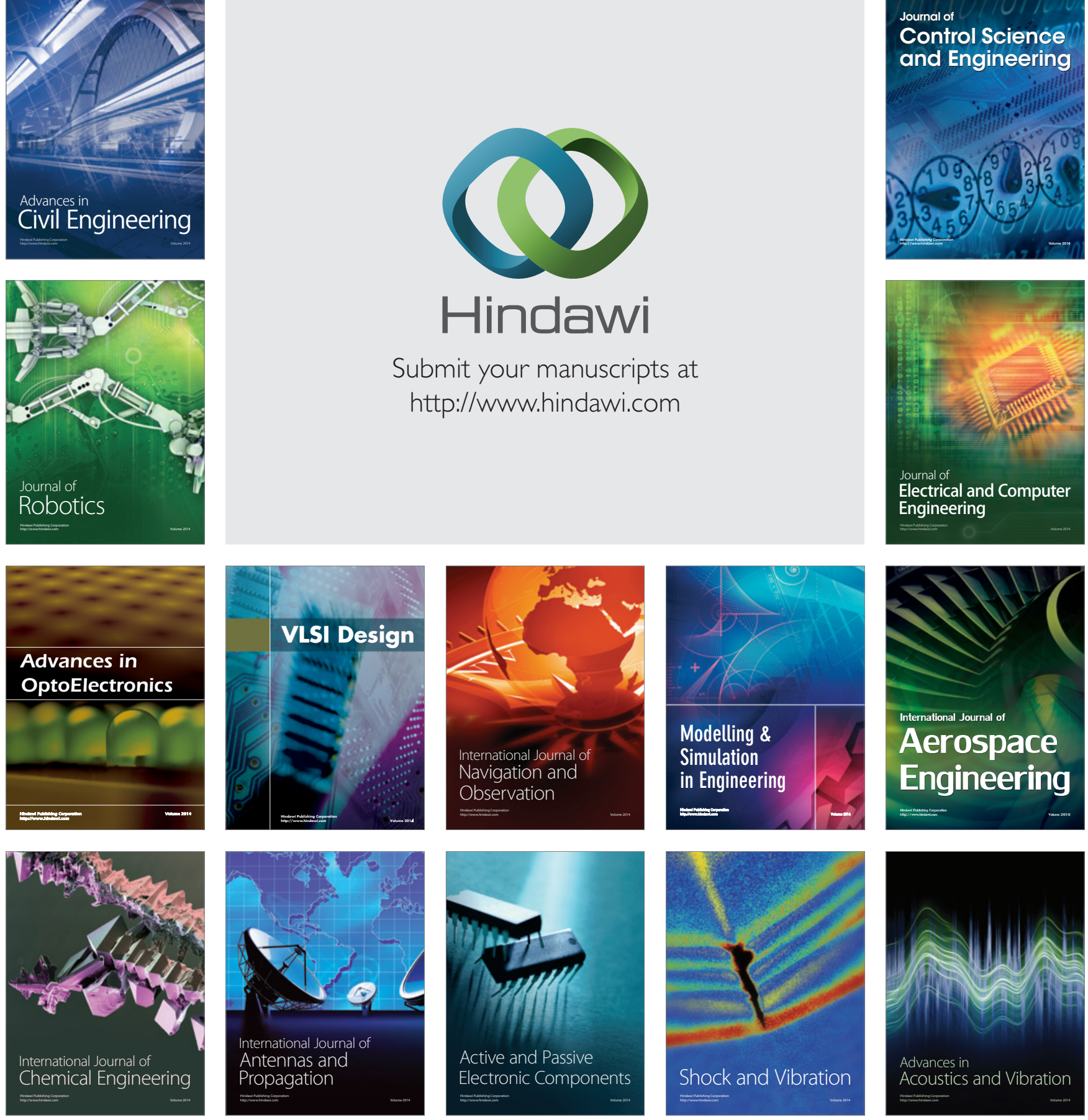